\title{
O Ensino de Ciências e a Saúde: por uma Docência Intercultural e Crítico-Reflexiva na Escola Básica
}

\section{Science Education and Health: Towards an Intercultural and Critical Reflective Teaching at School}

Fagner Henrique Guedes Neves ${ }^{1}$

Paulo Pires de Queiroz ${ }^{2}$

${ }^{1}$ Fundação Oswaldo Cruz (Fiocruz), Instituto Oswaldo Cruz (IOC), Programa de Pós-graduação em Biociências e Saúde, Rio de Janeiro, RJ, Brasil.

Autor correspondente: fagner.neves@ioc.fiocruz.br

${ }^{2}$ Universidade Federal Fluminense' (UFF), Faculdade de Educação, Niterói, RJ, Brasil.

Resumo: $O$ artigo relata o andamento de uma investigação sobre confluências entre uma perspectiva holística da saúde, a interculturalidade e a formação do professor de Ciências do ensino fundamental. A pesquisa buscou analisar os impactos de dinâmicas dialógicas e práticas pedagógicas interculturais nas impressões de licenciandos e professores da escola básica sobre a saúde e a educação intercultural. Utilizou-se uma metodologia participativa que permitiu planejar, experimentar e avaliar coletivamente práticas pedagógicas interculturais numa rede municipal de ensino da Região Metropolitana do Rio de Janeiro. O empreendimento tem favorecido reflexões críticas sobre os instrumentos e as finalidades da docência emancipatória, identificando uma significativa influência da interculturalidade na construção de conceitos e condutas voltadas à saúde física, mental e social. A análise pontua, ainda, que a proposta não pode ser limitada a escalas pontuais ou a momentos episódicos na esfera escolar, devendo ser cultivada diariamente na formação e na carreira docente.

Palavras-chave: Educação em saúde; Interculturalidade; Reflexividade crítica; Escola básica.

\begin{abstract}
This article reports a study, which explores confluences between health, interculturality and Sciences teacher training. The research deals with the contributions of interculturality to health, considering a holistic perspective of physical, mental and social wellness. The research seeks to analyze the impacts of dialogical dynamics and intercultural pedagogical practices in the assumptions that graduates and teachers of elementary school elaborate about health and intercultural education. A participatory methodology was used in order to plan, experiment and evaluate these practices at some schools in Greater Rio. At the moment, the project drafts some important critical reflections on emancipatory teaching, interculturality and health which go beyond the restricted scales of specific school spheres.
\end{abstract}

Keywords: Health education; Interculturality; Critical reflection; Basic education.

Recebido em: 30/01/2019

Aprovado em: 15/08/2019 
O presente trabalho investiga possíveis enlaces democráticos entre a saúde, a cultura e a educação escolar. Mais do que um assunto para médicos e hospitais, a saúde é uma preocupação pública de grande importância e que caberia ser pautada na escola básica. Em especial, procuraremos defender que a interculturalidade e a reflexividade crítica desempenham papeis fundamentais na capacitação de professores comprometidos com a promoção de uma educação em saúde mais igualitária e plural.

Dialogando com renomados teóricos como Canguilhem (1990) e Dejours (1986), problematizamos um conceito holístico da saúde: a ideia do bem-estar como uma construção coletiva e aberta a transformações, influenciada por fatores ambientais, psíquicos e sociais. Nesse âmbito, a interculturalidade pode ser compreendida como um gatilho de ideias e atitudes favoráveis à saúde da mente e do corpo e a escola, um ambiente propício para viabilização desse processo.

Conforme os Parâmetros Curriculares Nacionais (BRASIL, 1999), a saúde deveria ser tópico transversal no ensino fundamental. Contudo, na prática, a abordagem costuma ser reservada à disciplina de Ciências. Partindo dessa premissa, questionamos: como sujeitos licenciandos e docentes podem construir ideias e atitudes crítico-reflexivas que sejam favoráveis à promoção de uma educação em saúde de caráter intercultural na escola básica? Frente à pergunta, consideramos que o desenvolvimento de dinâmicas dialógicas e práticas educativas interculturais conjuntamente com licenciandos e docentes pode alavancar a produção de identidades profissionais comprometidas com a reflexividade crítica e a interculturalidade na educação em saúde da/na escola básica.

Nesse sentido, a investigação teve por objetivo analisar os impactos das dinâmicas e práticas pedagógicas propostas nas impressões de docentes em Ciências da escola básica sobre a saúde e a educação intercultural. Por meio de uma metodologia de pesquisa participativa, foram planejadas, experimentadas e avaliadas coletivamente práticas pedagógicas interculturais em espaços escolares. Admitimos, como recorte, o segundo segmento do ensino fundamental numa rede municipal de ensino da Região Metropolitana do Rio de Janeiro - do sexto ao nono ano.

O artigo é, pois, um breve relato de uma pesquisa em andamento, que estabelecerá interlocuções entre a definição de holística de saúde que vislumbramos e o ensino de Ciências na escola, enfatizando a importância da educação intercultural e da formação docente crítico-reflexiva no debate. Além de traçarmos as bases metodológicas do estudo, registraremos as problematizações e encaminhamentos mais significativos da investigação.

\section{Por uma Definição Holística da Saúde: Diálogos com Canguilhem e Dejours}

Na sua etimologia helênica e latina, o termo saúde designa "estado positivo do viver" (LUZ, 2009): um conjunto de hábitos prudentes e harmoniosos em todos os campos da existência que estaria totalmente livre de vícios, enfermidades e moléstias. Por séculos e séculos, imaginários de diversas culturas ratificam a ideia, associando a saúde à noção de bem-estar livre de doença.

A partir do século 19, o positivismo atribui um caráter científico à definição corrente de saúde. A teoria admite o bem-estar como o estado excelente e normal de funcionamento do organismo e doença como o desvio quantitativo de graus de hormônios, anticorpos ou substâncias, condição anormal de operação do organismo. 
Admitia-se a saúde, assim, como normalidade essencialmente fisiológica, cuja administração seria privilégio de médicos e hospitais.

Na década de 1940, contudo, a Organização Mundial da Saúde (OMS) amplia o entendimento do que é saúde, afirmando-a como “bem-estar físico, mental e social”. Emerge, assim, uma concepção multidimensional da saúde, que a examina num complexo conjunto de fatores: ambiente, alimentação, higiene e estruturas psíquicas, econômicas, políticas e culturais. Prevalece, no entanto, ainda a noção da saúde excelente, estado normal e estável de bem-estar, porém tal condição nunca é factível, como a investigação acadêmica e a própria OMS apontariam mais tarde.

Ora, o bem-estar nunca pode ser considerado a ausência de doença, visto que a condição humana é, em si, mutável e imperfeita. Ele é, antes, um processo dinâmico de interação entre os aspectos fisiológico, psíquico e coletivo da existência humana, sempre perpassado por ressignificações. O que está em cena é a construção de uma definição holística da saúde, visão que tem as suas raízes, principalmente, no pensamento do filósofo e médico francês Georges Canguilhem, em especial na obra O normal e o patológico, lançada em 1966. Este passou a ser o discurso afirmado por um vasto debate acadêmico (ALMEIDA FILHO, 2000; ALVES, 2013; COELHO; ALMEIDA FILHO, 1999; DEJOURS, 1986; LUZ, 2009; SAFATLE, 2011; SCLIAR, 2007) e pela Carta de Ottawa, documento resultante da I Conferência Internacional sobre Promoção da Saúde, organizada pela OMS em 1986.

A originalidade da proposta de Canguilhem (1990) está em romper com o positivismo médico e sua percepção da saúde e da doença, problematizando o conceito de normalidade subjacente ao debate. Para o autor, o que está em questão não é somente o movimento orgânico, mas a relação de cada organismo com os ambientes em que se situam. O que diferencia saúde e doença não seriam variações quantitativas entre os órgãos do corpo, e sim a capacidade de o organismo produzir as suas normas em todos os contextos. Ou seja, tratase de uma distinção qualitativa que exige, assim, instrumentos compreensivos alternativos.

Discutindo com o positivismo de Auguste Comte, Claude Bernard e René Leriche, Canguilhem (1990) desloca a discussão sobre a saúde do orgânico ao multidimensional. Em sua perspectiva, não há como falar de um organismo saudável em si, mas em relação ao espaço físico e social em que atua. Bem-estar diz respeito à capacidade do sujeito de normatizar a sua existência, infringindo normas que ele mesmo propôs e elegendo novas normas, diante das circunstâncias. Inversamente, o mal-estar caracteriza um estado de impotência do sujeito frente a um determinado contexto, onde há imposição de normas ao invés de produção ativa e própria. Mudam as situações e o organismo não é suficientemente capaz de determinar-se.

A proposta canguilhemiana é, sem dúvida, desestabilizadora. A norma é sempre uma ideia relativa. A pressão arterial pode ser patológica para uns e não ser para outros. A miopia não é tão perturbadora ao funcionário público quanto é para o motorista. Viver em terras muito altas pode ser nocivo a uns enquanto pode não ser a outros. Em suma, um quadro somente é patológico se representar alguma desvantagem ou impotência que cause sofrimento. Saúde não é, essencialmente, algo somente sobre o fisiologismo, como também trata acerca da potencialidade de autonomia ou heteronomia do organismo diante de cada contexto em que se encontra. Se dispuser das ferramentas para a normatização de sua vida numa interação específica com o espaço físico e social, o sujeito será saudável naquela circunstância. Para Canguilhem (1990) existem, portanto, vínculos de interdependência entre o psíquico, o social e o somático. 
O legado de Canguilhem se materializa na construção de um campo de estudos da saúde bastante impactante no universo acadêmico (COELHO; ALMEIDA FILHO, 1999). Um campo certamente polêmico, pois questiona poderes-saberes da medicina e do positivismo médico há muito tempo estabelecidos na academia e no senso comum, influenciando muitos pesquisadores, a exemplo do psicólogo Christophe Dejours.

Para Dejours (1986), efeitos psicossomáticos diferenciados são produzidos conforme os modos como os sujeitos vão tecendo as suas relações com o meio físico através do trabalho social. Certos exercícios tenderiam a causar estados mentais e físicos saudáveis ou patológicos, que se alternariam durante toda a vida.

Dejours (1986) caracteriza a saúde como a atividade de satisfação dos desejos físicos, mentais e sociais do homem. E, como propõe Canguilhem (1990), o bem-estar é consequência da liberdade que o indivíduo tem de "regular autonomamente" sobre a satisfação dos movimentos fisiológicos, mentais e sociais fundamentais. Consiste na possibilidade e no compromisso do ser humano de decidir autonomamente sobre o corpo e a mente e deliberar livre e dialogicamente acerca do trabalho social. Interações "penosas", sustentadas por normas e valores autoritários, tolhem a liberdade e a autonomia, desencadeando estados angustiantes os quais, somatizados pelo organismo, abrem caminho para patologias. E o mesmo se verifica quanto à completa ociosidade, que se opõe à natural disposição do organismo de, ativamente, regular-se. Nesta perspectiva, o bem-estar deve ser necessariamente compreendido como uma atividade do organismo e da mente em interação com a coletividade.

Canguilhem (1990) e Dejours (1986) apelam, portanto, a uma concepção holística da saúde, como fenômeno no qual o fisiológico, o psíquico e o coletivo são interdependentes e suas relações são sempre abertas a transformações. O mau funcionamento do organismo impacta o bem-estar mental e, por sua vez, compromete a qualidade das interações sociais empreendidas pelo indivíduo. Instabilidades psíquicas provocam variações no organismo e nas relações sociais. $E$, por sua vez, as diferentes espécies de interações coletivas também desencadeiam estados mentais e somáticos distintos.

É nesse sentido que gostaríamos de convidar o leitor e a leitora a uma reflexão sobre a cultura como um campo crucial de produção da saúde, inclusive na educação básica. Problematizamos a educação escolar em saúde, em especial no ensino de Ciências, como um possível espaço e processo intercultural, que possa desenvolver ideias e atitudes compatíveis com o bem-estar holístico. Consideramos fundamental que os professores sejam qualificados para desenvolver um ensino como tal.

\section{A Educação Intercultural em Saúde no Ensino de Ciências: um Desafio posto à Formação Docente}

Pode não estar claro para muitas pessoas, mas a socialização é um fator de importância significativa na promoção da saúde. O conflito cultural tende a ser um dos mais claros gatilhos do mal-estar na atualidade e que torna necessária a adoção de alternativas sociais compatíveis com o bem-estar.

Historicamente, a pluralidade cultural tem sido um fator de maximização da desigualdade e da padronização nas sociedades. Desde a antropologia de LéviStrauss (1996) pode-se identificar que as diferenças culturais costumam ser concebidas num sentido negativo: como uma ameaça aos padrões da cultura dominante. 
A adesão ao cânone é colocada como essencial, sob pena da segregação ou da eliminação dos discordantes. Segundo diversos autores, esses mecanismos são desenvolvidos também na gestão educacional, ora impondo aos grupos minoritários a assimilação dos padrões dominantes, ora excluindo esses grupos da convivência nos estabelecimentos educativos (FORQUIN, 1994; MCLAREN, 1997). Não é demasiado afirmar que interações como essas contribuem bastante para intensificar mal-estar psicossomático. Nessa direção, compreendemos que espaços e processos mais pendentes à saúde do que à patologia são possíveis mediante a contínua deliberação coletiva por um cenário democrático.

Nessa direção, a interculturalidade emerge como uma alternativa desejável (BHABHA, 2010; SANTOS, 2007; TODOROV, 2010). Trata-se de um enfoque da diversidade cultural que chama a sociedade à adoção de outro olhar: a articulação entre a igualdade entre as culturas e a valorização de suas diferenças. Uma perspectiva na qual o diálogo entre todas as lógicas, ideias e experiências produzidas pelas culturas seja considerado um quesito fundamental à justiça social. Não há como falar em igualdade quando há imposições ou exclusões. Acreditamos no diálogo intercultural como processo em que todos são convidados a produzir as normas que orientam as suas vidas, impactando assim positivamente os seus sistemas mentais e fisiológicos. Assim, convém criar na educação em saúde, espaços participativos de livre interlocução que possibilitem mútuas aprendizagens entre as culturas, valorizando as suas contribuições à construção de um espaço social mais democrático (BRICEÑO-LEÓN, 1996). E um desses locais pode e deve ser a escola básica.

Com efeito, a saúde é uma demanda claramente identificável nos Parâmetros Curriculares Nacionais (PCN) ${ }^{1}$. Em conformidade com as finalidades do ensino fundamental pontuadas pela Lei no 9.394/96 e as Diretrizes Curriculares Nacionais (BRASIL, 1998), a Secretaria de Educação Básica do Ministério da Educação (MEC), em debate com especialistas e professores da educação básica de todo país, desenvolve os marcos oficiais norteadores e prescritivos da educação escolar em saúde. O tópico é abordado no volume transversal Saúde e no tomo Ciências da natureza, matemática e suas tecnologias. Como na prática, porém, a educação em saúde tem sido uma questão cara ao ensino de Ciências e uma evidente lacuna nas outras disciplinas, analisemos o volume dedicado às Ciências Naturais.

A saúde é um dos eixos temáticos do $P C N$, ao lado do ambiente e dos recursos tecnológicos. No documento, mais do que um fenômeno fisiológico, a saúde é compreendida como fato holístico, no qual a estrutura biológica está em constante interação com o ambiente e com os artefatos materiais e sociais fabricados pelo ser humano. Multidimensionalidade e processualidade são os pilares de uma concepção educativa que tem como a sua meta principal "[...] compreender o corpo humano como um todo integrado e a saúde como bemestar físico, social e psíquico do indivíduo" (BRASIL, 1999, p. 58). Nessa direção,

O equilíbrio do corpo depende das suas interações com o meio. [...] Com esse olhar estuda-se, neste ciclo, o corpo, algumas de suas funções e seu estado de equilíbrio, isto é, a saúde. Uma disfunção de qualquer aparelho, sistema ou órgão representa um problema do organismo todo. Da mesma forma, alterações no ambiente afetam o organismo. (BRASIL, 1999, p. 62).

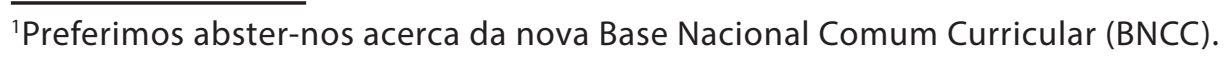


Deve ser uma meta do ensino de Ciências o trato de uma perspectiva holística da saúde, firmada no "[...] estabelecimento de relações entre aspectos biológicos, afetivos, culturais, socioeconômicos e educacionais na preservação da saúde para compreendê-la como bem-estar psíquico, físico e social" (BRASIL, 1999, p. 66). Tal concepção pode ser posta em prática

[...] por intermédio de estratégias variadas os alunos podem construir a noção de corpo humano como um todo integrado, que expressa as histórias de vida dos indivíduos e cuja saúde depende de um conjunto de atitudes e interações com o meio, tais como alimentação, higiene pessoal e ambiental, vínculos afetivos, inserção social, lazer e repouso adequados (BRASIL, 1999, p. 62, grifo nosso).

É significativa a veiculação no PCN da ideia da socialização como um fator da saúde global do ser humano. Parâmetros para o primeiro ciclo do ensino fundamental revelam que a proposição pode assumir um significado intercultural:

É importante que o professor incentive seus alunos a valorizarem as diferenças individuais, seja quanto à cor, à idade, ao corpo, seja quanto ao ritmo de aprendizagem ou às diferenças socioculturais. O professor, trabalhando num clima de cooperação e solidariedade com sua classe, favorece a autoestima e a formação de vínculos entre os integrantes do grupo (BRASIL, 1999, p. 51).

O PCN sugere, ainda que escassamente, uma visão da educação em saúde como um espaço de encontro, comunicação e valorização das diferenças culturais. Uma instância em que todos são chamados a desempenhar papeis de autonomia frente ao meio em que vivem, construindo dialogicamente estados de bem-estar. Este poderia ser o pressuposto da aprendizagem de um conceito de saúde holístico no segundo segmento do ensino fundamental.

Por certo, um ensino como tal pressupõe a reconfiguração das linguagens, espaços, tempos e conhecimentos escolares usuais (MOREIRA; CANDAU, 2008). O PCN sugere o uso de metodologias didáticas ativas como pesquisas de campo e visitações pedagógicas a unidades de saúde (BRASIL, 1999, p. 64-65), por exemplo. Por nossa vez, propomos o uso das imagens desestabilizadoras, artifício proposto por Boaventura de Sousa Santos (SANTOS, 1996) para estranhamento e desnaturalização dos preconceitos culturais correntes nas práticas sociais. Tais imagens podem ser ideias, pessoas ou objetos cuja menção problematiza o conflito cultural, gerando um sentimento de inconformismo perante a sua continuidade. A educação em saúde é um campo fértil a imagens como essas. Filmes e fotografias de lixões habitados por comunidades abandonadas pelo Estado ou de crianças africanas desnutridas, gráficos e altos indicadores referentes a síndromes advindas do trabalho social... Imagens e atividades como tais poderiam colaborar à construção intercultural de um conceito de saúde holístico nas escolas.

Contudo, como tornar exequível o proposto? Estariam os professores qualificados a responder ao desafio? A formação docente ainda não está amplamente orientada por uma filosofia que favoreça a atividade profissional coerente com o projeto de uma educação intercultural em saúde. 
É patente para o debate acadêmico que os cursos de licenciatura têm sido significativamente dirigidos por uma perspectiva tecnicista, fomentada pelo Banco Mundial e ratificada por políticas educacionais em todo o mundo. Essa concepção afirma que à docência só é preciso dominar conhecimentos científicos e técnicas pedagógicas descontextualizadas, propostas por especialistas. Tal modelo nega a importância de saberes que se constroem em meio às experiências docentes nas realidades escolares específicas. Propicia-se, assim, um afastamento entre o que se ensina nesses cursos e os problemas concretos das escolas e da sociedade, comprometendo a qualidade da educação básica e da formação cidadã.

É imprescindível repensar a docência, visando responder às demandas feitas pela educação escolar, dentre elas a interculturalidade e a educação em saúde. Para isso, cabe entender esse exercício profissional como um fenômeno reflexivo e crítico (NÓVOA, 1992; PIMENTA; GHEDIN, 2005; QUEIROZ, 2012; TARDIF, 2005).

Os estudos sobre a reflexividade crítica na formação de professores são bastante influenciados pelas discussões de Schön (1983) acerca do desenvolvimento do senso reflexivo e investigativo dos trabalhadores sobre as suas próprias experiências laborais. Nesse debate, um aspecto dessa perspectiva é largamente contestado: seu escasso compromisso social. Admitindo a importância da reflexividade ao aprimoramento da docência, a corrente critico-reflexiva pontua que esse movimento sempre deve envolver um esforço de crítica às condições e implicações sociais da atividade docente.

Em diálogo com vertentes da teoria crítica (PIMENTA; GHEDIN, 2005), a concepção crítico-reflexiva propõe uma reconstrução da profissão docente. Essa perspectiva considera imprescindível que, nesse espaço, teoria e prática estejam de mãos dadas, através do estudo articulado, e sem hierarquizações, de saberes científicos, pedagógicos e experienciais. Convém que formadores de professores, licenciandos e professores da escola básica realizem pesquisas conjuntas sobre as condições históricas, pedagógicas, culturais, políticas e pessoais em que a docência está inserida, propondo respostas aos desafios da educação escolar. E um desses desafios é a promoção de práticas pedagógicas interculturais voltadas para a construção da autonomia e emancipação do profissional docente na educação em saúde.

A educação em saúde no ensino de Ciências da escola básica é um objeto ainda incipiente no debate acadêmico nacional. Nos últimos cinco anos, foram escassos os estudos veiculados em artigos qualificados pela Coordenação de Aperfeiçoamento de Pessoal de Nível Superior (CAPES). Os artigos tratam sobre currículo e materiais pedagógicos (ARAÚJO; AMORIM, 2014; ASSIS; ARAÚJO-JORGE, 2014; ASSIS; PIMENTA; SCHALL, 2013; FRANÇA; MARGOLANI; SCHALL, 2014) e formação docente (SAMPAIO; ZANCUL; ROTTA, 2015; SOARES; CHAPANI, 2015). Contudo, a interculturalidade é um aspecto negligenciado nas análises. Trata-se de um debate que merece ser pautado pela investigação acadêmica e é esse o panorama em que desenhamos a investigação.

\section{O Desenho Metodológico}

Frente ao objetivo da pesquisa, lançou-se mão de uma metodologia participativa que permitisse tanto produzir conhecimento sobre uma realidade ao lado dos agentes diretamente incumbidos de sua produção diária quanto transformá-la, imprimindo-lhe direções mais democráticas. 
Reuniram-se, para isso, mediante a assinatura de Termo de Consentimento Livre e Esclarecido (TCLE), dez professores de Ciências da rede pública de ensino básico de um município da Região Metropolitana do Rio de Janeiro, cinco licenciandos de curso de Ciências Biológicas de uma Universidade pública do Rio de Janeiro, um doutorando, e dois professores atuantes em instituições federais de ensino superior e pesquisa. A partir da identificação e da análise dos problemas de estudo, propostas de modificação dos rumos da prática foram encaminhadas à ação, fomentando novas rodadas de reflexões e intervenções que aprimorassem as práticas (ELLIOTT, 1991; PIMENTA, 2005; THIOLLENT, 1986).

Empreenderam-se atividades colaborativas de reflexão crítica sobre a construção de currículos e práticas de ensino interculturais em saúde na escola básica, por meio da realização de oficinas pedagógicas (CANDAU et al., 1995) e rodas de conversa conjuntamente com os sujeitos da pesquisa. Configurou-se nos encontros uma concepção crítico-reflexiva da formação de professores, fomentando o desenvolvimento pessoal e profissional docente e das instituições escolares. As oficinas e rodas de conversa problematizaram a importância da produção de leituras críticas sobre a sociedade contemporânea, as identidades culturais e seus conflitos e tensões inerentes, o monoculturalismo típico da escola e as possibilidades de promoção de um ensino de saúde intercultural nesse quadro. As discussões buscaram conferir aos atores instrumentos pedagógicos que Ihes permitissem, com autonomia e reflexividade crítica, propor práticas interculturais de educação em saúde no cotidiano escolar, avaliar o seu próprio trabalho, bem como deliberar e implementar intervenções que o aperfeiçoem.

Nas oficinas, emergiram muitas impressões a respeito das potencialidades e implicações da interculturalidade no cotidiano escolar. Planejamentos e atividades diversas que buscavam trabalhar a educação intercultural da saúde foram operacionalizados em diferentes performances, durante as aulas de Ciências no ensino fundamental, o nível primário da organização escolar no Brasil. Duas rodas de conversa com os participantes permitiram avaliar o processo, reelaborar planos e encaminhar novas intervenções. Todos os encontros foram documentados com o auxílio de recursos audiovisuais específicos.

Foi desenhada, pois, uma "espiral" de movimentos de reflexão, ação e reflexão em proveito de uma educação intercultural e emancipatória. Os procedimentos favoreceram reflexões e intervenções profícuas nas identidades profissionais dos participantes.

\section{O Campo de Pesquisa: Reflexões e Proposições}

Dando voz e escuta aos sujeitos da investigação, foi possível registrar achados muito esclarecedores sobre o universo concreto onde propomos nossas perspectivas de ensino básico e formação docente. Em termos gerais, pudemos identificar que a proposta que vislumbramos certamente pode se materializar no cotidiano escolar, embora os efeitos concretos dessa iniciativa ainda sejam bastante incipientes no espaço escolar.

Por um lado, a pesquisa permitiu construir, com professores e licenciandos, ideias e atitudes significativas em prol da educação intercultural em saúde, no âmbito de uma docência crítico-reflexiva. Por outro lado, essa proposta esbarra numa série de obstáculos inerentes tanto à estrutura social quanto à cultura escolar. Parece haver uma distância entre a intencionalidade do discurso e a efetividade da ação. 
Frente ao cenário identificado, consideramos como um recurso analítico frutífero o dualismo entre autonomia e heteronomia. Nosso parecer é que os achados podem ser analisados com o recurso à dicotomia entre duas normatividades vitais (CANGUILHEM, 1990; SAFATLE, 2011): uma norma elaborada pelo sujeito, que favorece seu bem-estar, e outra norma, imposta a ele em suas interações com os ambientes físico e social, que prejudica a sua saúde. O par autonomia-heteronomia perpassa todos os três eixos teórico-conceituais em que a pesquisa se estabelece: saúde, interculturalidade e reflexividade crítica.

Organismo saudável é aquele que exerce sua autonomia diante do ambiente (CANGUILHEM, 1990). Por sua vez, a interculturalidade é um processo de emancipação plural, de governança partilhada por todos os grupos culturais (BHABHA, 2010; SANTOS, 2007; TODOROV, 2010). E a reflexividade crítica é uma radical negação ao tecnicismo, paradigma que produz a heteronomia do professor (NÓVOA, 1992; PIMENTA; GHEDIN, 2005; QUEIROZ, 2012; TARDIF, 2005). Heteronomia esta que impossibilita a educação intercultural e, por sua vez, engendra mal-estar no espaço escolar, para todos os envolvidos. De outro modo, se pensarmos numa formação docente firmada num princípio reflexivo e crítico de autonomia profissional, as interações no espaço pedagógico escolar poderiam seguir-se na mesma direção, imprimindo efeitos benéficos à saúde de todos. Estes dois modelos heurísticos poderiam ser muito úteis à análise que propomos. Procuramos, assim, apreciar os resultados da pesquisa à luz desse enfoque.

Ao todo, foram empreendidas quatro oficinas e duas rodas de conversa acerca da educação intercultural da saúde na escola básica e da formação de seus professores. Cada oficina foi desencadeada a partir de alguma "imagem desestabilizadora" (SANTOS, 1996) e possibilitou rodadas de reflexões dialógicas e problematização de alternativas pedagógicas. Após a experimentação concreta no cotidiano escolar, as rodas de conversa subsidiaram avaliações dos resultados e deliberações de novas práticas, em uma série de ações ainda em curso.

Nesse sentido, a primeira oficina abordou a saúde como "bem-estar físico, mental e social" dialogando com Canguilhem (1990), Dejours (1986) e os Parâmetros Curriculares Nacionais (BRASIL, 1999). Partiu-se do relato de experiência de uma professora da escola básica, no qual se enfatizava a síndrome de Burnout advinda de décadas de atividade docente numa favela do Rio de Janeiro. A visão da docência na instituição escolar como um exercício cujas mazelas estruturais engendram quadros patológicos entre os professores chamou atenções à multidimensionalidade do conceito de saúde em debate e à sua construção cotidiana.

A oficina estimulou um questionamento à perspectiva organicista da saúde, em prol de um ponto de vista mais atencioso aos enlaces entre o físico, o mental e o social que caracterizam o conceito. Também foi marcante a constatação do saudável e do patológico como fenômenos relativos, transitórios e alternantes numa complexa produção de estados de bem-estar ou mal-estar, individuais e coletivos. A discussão propiciou resultados significativos: 
[...] ficou claro para mim que a saúde é algo mutável e que quadros saudáveis $e$ patológicos podem se alternar ou até mesmo ter concomitância num certo organismo ou ambiente. [...] É necessário que essa ideia seja mais levada em conta no ensino e na aprendizagem na escola. [Professora participante].

o que me surpreendeu na oficina é que saúde é muito mais do que somente o bemestar do corpo, mas também da mente e da sociedade. Uma escola democrática tem a obrigação de repensar o ensino da saúde, considerando como ele é um processo sempre em transformação. [Licenciando participante].

A primeira oficina tornou patente a importância da adoção de um conceito multidimensional e processual da saúde no currículo de um ensino de Ciências ainda pouco afeito à proposta. Ficou clara a ideia da saúde como produção de norma, autonomia do organismo frente ao meio. Isso significou tocar num pilar da formação específica do professor de Ciências: o foco no processo fisiológico humano em detrimento de um olhar acurado sobre a interação desse fenômeno com as dimensões mentais e ambientais [físicas e sociais] onde esse organismo se insere.

Muitos participantes consideram que a sua formação específica é pouco comprometida com a noção de uma saúde holística, em que pesem as orientações do Ministério da Educação. Para eles, a visão fisiológica, organicista, parece dominar a formação do professor de Ciências e influenciar a maneira como o assunto é abordado nas escolas. Como disse um professor que está participando da pesquisa, "[...] temos que fazer alguma coisa para mudar a formação que temos tido, para contemplar o fato de que saúde não é só uma questão do corpo, mas uma interação do corpo e da mente com o meio físico e social". Antes, porém, é preciso problematizar o viés ético-político intercultural que essa formação pode ter. No encontro seguinte, procurou-se abordar a "inserção sociaL" (BRASIL, 1999) como um determinante dos elementos mental e físico do bem-estar, em especial no ensino básico.

Sendo assim, a segunda oficina procurou configurar uma análise da interculturalidade como proposta favorável ao bem-estar coletivo no espaço escolar. Para tanto, elaborou-se uma crítica à tendência monocultural das culturas escolares. Partiu-se de impressões da escola veiculadas por excertos selecionados do clipe Another brick in the wall, da banda Pink Floyd (1979), e do filme Entre os muros da escola (2008) dirigido por Laurent Cantet. Comparações entre os vídeos foram bastante frutíferas. O clipe põe em relevo a figura da didática monolítica, repressiva e desinteressante que se pereniza no imaginário social e na prática escolar. Já os trechos do filme evidenciaram os conflitos culturais presentes numa escola do subúrbio de Paris e que desafiam a docência de qualidade a repensar os seus padrões pedagógicos, que muitas vezes constroem a heteronomia e o mal-estar dos alunos. Tanto uma quanto a outra peça são imagens da clássica recusa da escola em admitir a diversidade como um aspecto crucial ao sucesso da educação democrática. Nesse sentido, foram comuns depoimentos como tais:

Desde a época em que era aluna, tenho tido a impressão [de] que existe na escola uma falta de sensibilidade com o 'outro' [...] um ser que [...] pode construir uma sociedade melhor pelo diálogo. Tratam a todos como se fossem 'iguais', sem qualquer respeito [...] [Licencianda participante].

[...] me parece que a escola não se agrada da diversidade nem da inovação de ideias e práticas. A escola parece deslocada do que acontece na sociedade e das suas questões mais urgentes [...] e fazer as diferenças conviverem é um problema que está na 'pauta do dia' $^{\prime}$ [Professora participante]. 
O que mais eu vejo são reações violentas e indisciplinadas de alunos cujas culturas não são aceitas pela escola [...] Noto também que mais e mais colegas meus [professores] têm ficado depressivos e reféns de medicamentos por causa dos conflitos com esses alunos, mas repensar a própria prática em termos interculturais pouca gente quer [...] Cada vez mais penso que a cultura escolar é mais um lugar de mal-estar do que de bemestar [Professor Participante].

A orientação monocultural da escola não é, pois, novidade à pesquisa educacional e aos educadores. Contudo, negar às culturas a participação ativa no ensino e na aprendizagem compromete sobremaneira a socialização democrática no lócus escolar e conduz a estados patológicos, como no caso do relato da professora na primeira oficina. Sensações de impotência e esgotamento frente ao vivido fazem do ensino e da aprendizagem processos angustiantes, nada saudáveis.

A escola é um ambiente patogênico em potencial, ao mesmo tempo em que pode contribuir à saúde. A cultura escolar e seus dogmáticos ditames político-pedagógicos fazem adoecer a mente e o corpo, tornando muitos professores, funcionários e alunos reféns de medicações e terapias. Entretanto, os sujeitos participantes também falam com orgulho da convivência na escola, ressaltando-a como um lugar de realização pessoal e de troca com o outro. É claro que isso não significa que eles nunca sintam as dificuldades concernentes à sua rotina profissional, porém buscam observá-la sob os seus ângulos agradáveis. Estaríamos, assim, diante de "faces de uma mesma moeda": aspectos de um universo no qual a saúde e a doença se relacionam dia-a-dia, onde a autonomia do sujeito frente ao meio e a heteronomia parecem estar em tensão continuamente. Sendo assim, fica evidente, uma vez mais, que a saúde não é um estado imutável de bem-estar, mas um processo marcado por constantes transformações de acordo com as interações do ser humano com o ambiente.

De acordo com a maneira como é administrada nos espaços coletivos, a diversidade pode alavancar ora o bem-estar, ora o mal-estar. Nesse quadro, são inúmeras as evidências das moléstias e doenças advindas de um cenário social marcado por exclusões. Em tal âmbito, a interculturalidade emerge como uma possível alternativa, cuja potencialidade no espaço escolar está para ainda ser mais explorada. Partindo destes referenciais, empreenderam-se, na oficina, atividades que estimularam representações renovadas de si, do próximo e da sociedade, em sentidos igualitários e plurais.

$\mathrm{Na}$ dinâmica, os participantes se mostraram bastante inclinados à educação intercultural. No entanto, seu parecer geral foi que lhe faltavam a qualificação profissional requerida para tal tarefa, conforme um professor declara: "Fui preparado para realizar a educação bancária, sem reflexão e crítica sobre as culturas de pertencimento dos sujeitos do processo educativo" E outra professora participante diz: " $A$ 'verdade' é que um ensino intercultural da saúde é um projeto muito complicado!". Diante do quadro, a pesquisa buscou afirmar que a educação intercultural da saúde é viável através da contínua construção de uma qualificação docente crítico-reflexiva nos cursos de licenciatura e no contexto escolar. Ou seja, procurou-se problematizar uma formação para a autonomia do professor e, por extensão, dos estudantes.

Sendo assim, a oficina terceira problematizou o cenário atual da formação de professores, à luz de suas condições estruturais e compromissos políticos inerentes. Esteve em discussão a supremacia do tecnicismo como o princípio norteador de uma capacitação descontextualizada e reprodutivista, pouco afeita à liberdade e à criatividade profissional que devem caracterizar um ensino emancipatório. A dinâmica partiu das figuras da 
disciplina de Pesquisa e Prática de Ensino e do estágio na escola básica para problematizar a reflexividade crítica como uma alternativa desejável na reconfiguração de uma nova docência na escola básica. O debate promoveu uma importante desestabilização de lugarescomuns relativos ao modelo tecnicista, convergindo ao entendimento de que a educação intercultural requer professores conscientes acerca do processo educativo e de seus espaços, tempos, atores e saberes estruturantes para estimularem, com maior probabilidade de sucesso, diálogos e aprendizagens mútuas entre as culturas no ensino.

Para operacionalizar a formação profissional que se vislumbra, a oficina seguinte proporcionou um laboratório de experimentação pedagógica. Foram desenvovidas ações de elaboração, avaliação e retificação de estratégias que alavancassem práticas interculturais de ensino da saúde na escola. Os resultados foram profícuos. Um licenciando propôs uma aula que lograsse "Identificar as consequências ambientais, sociais e mentais decorrentes da moradia em aterros sanitários". Outra licencianda teve em mente, como objetivo de sua atividade, "Problematizar o uso de células tronco no tratamento de doenças à luz da bioética". Em geral, os planos partiram de expedientes de desestabilização do senso comum, através de figuras, músicas ou vídeos, articulando aulas expositivas com abordagens pedagógicas lúdicas de estímulo à reflexão discente. A atividade teve em vista incentivar os sujeitos como produtores de suas normas profissionais, como pressuposto fundamental da construção de um ensino em que o aluno também seja como tal.

Quando, porém, passou-se à implementação do pactuado, os efeitos observados variaram caso a caso:

\begin{abstract}
No início não foi fácil [empreender um ensino em termos interculturais], pois tive que abandonar convicções que tinha há muito tempo. Tive que refletir mais e planejar as aulas, aprofundando o meu domínio do saber específico da minha disciplina e dos saberes pedagógicos, construindo uma proposta mais atenta à diversidade representada pelos alunos e também mais comprometida com a qualidade do ensino básico. O problema é que muitos colegas meus não tem essa consciência. [Professor participante].

Não consegui colocar em prática o que fiz na oficina [...] Os alunos estavam muito dispersos e desatentos e ouvi reclamações de alguns pais de alunos. Não queriam 'nada' com a aula. Acredito que não pude despertar a curiosidade deles para a saúde como um fenômeno multidimensional e aberto a transformações. [Licencianda participante].
\end{abstract}

Muitas, pois, foram as dificuldades alegadas pelos sujeitos após a promoção das alternativas deliberadas. Os registros de campo permitem associar tais entraves a determinados aspectos pertinentes ao cotidiano escolar, tais como a agenda políticopedagógica da escola e as reações dos alunos à proposta. Estes termos se articulam numa frutífera roda de conversa e em novos encaminhamentos práticos.

Por um lado, é patente na escola a escassez de oportunidades de deliberação coletiva sobre as suas pautas pedagógicas e políticas, a despeito da proliferação de ritos burocráticos cada vez mais numerosos e exigentes. Tal desenho institucional favorece a emergência de uma cultura profissional individualista, que confere possibilidade à realização de todo tipo de proposta educativa sem um debate aprofundado sobre os seus princípios, objetivos e resultados. E o que ficou claro nos depoimentos foi a marcante supremacia de um ensino tecnicista, monocultural e pouco comprometido com o conceito holístico da saúde que vislumbramos. 
Por outro lado, os depoimentos também associaram as dificuldades enfrentadas ao posicionamento refratário dos alunos às inovações propostas. As avaliações dos achados convergiram à ideia de que ambos os processos, em verdade, decorreriam da reprodução de um senso comum que tende a negar a riqueza da diversidade e o valor da comunicação entre as culturas como processo criativo de uma socialização mais democrática. Impressões preconceituosas afloram em condutas discriminatórias entre os alunos (racismo, machismo, homofobia, intolerância religiosa) e muitos dos participantes encontram problemas em executar seus planos de aulas.

Os achados não chegam a surpreender, se considerarmos a escola como microcosmo de uma sociedade onde o diálogo democrático não costuma ser privilegiado. Em uma cultura que sistematicamente enfatiza a reprodução acrítica e o conformismo aos ditames hegemônicos, esse tipo de comunicação surge como tabu ou objetivo inviável. Como construir um conceito e uma prática de saúde baseada na ideia de autonomia num espaço que parece tender à heteronomia? Se falamos de uma autonomia para todos, como construí-la fora de uma esfera pública dialógica, onde todos possam, realmente, exercer essa autonomia? A pesquisa permitiu identificar muitos obstáculos que se colocam diante desse projeto. Entretanto, cabe ir além da constatação e propor novas intervenções pedagógicas.

Mesmo assim, percebemos que desenvolver dinâmicas dialógicas e práticas educativas interculturais conjuntamente com licenciandos e docentes pode, sim, alavancar, pouco a pouco, identidades profissionais comprometidas com a reflexividade crítica e a interculturalidade na educação em saúde da/na escola básica. Sem dúvida, as atividades desenvolvidas na investigação podem ser consideradas como imagens desestabilizadoras do imaginário social que se cultiva em torno da educação escolar, em prol de rupturas interculturais manifestadas nos depoimentos. Não obstante, muito há a ser feito nessa direção, posto que as resistências ao projeto continuam bastante pronunciadas na cultura escolar e na sociedade.

No que se refere à educação intercultural em saúde, os resultados revelam um confronto entre autonomia e heteronomia, que se apresenta também como uma oposição entre potencialidade e impotência. De um lado, emergiu uma riqueza de ideias e atitudes em torno de uma educação intercultural em saúde na disciplina de Ciências. De outro lado, os entraves à efetividade desses pensamentos e condutas parecem muito difíceis de ser transpostos. A produção das normas do viver consiste numa tarefa muito desafiadora na escola popular. No entanto, a pesquisa mostra que essa construção não é só desejável como é possível. Nesse sentido, algumas questões e proposições emergem da reflexão, quais sejam:

(1) Pode-se 'ministrar' a saúde holística, como uma receita médica ao paciente? Não. Esta é uma produção autônoma do sujeito e não uma prescrição. À semelhança do construtivismo, a saúde holística é um processo de elaboração ativa de si, em interação com o meio. Em verdade, convém mediar, facilitar a dinâmica do bem-estar de outrem. Este deveria ser o papel de todos os agentes de saúde, dentre eles, na escola basica, o professor. Pensada nessa perspectiva, a escola poderia se tornar não somente um espaço de educação em saúde, mas também de educação na saúde, de promoção da saúde. Não somente um lugar em que se aborda uma concepção holística de bem-estar como também onde se produz esse estado continuamente. 
(2) Nessa direção, a socialização tem importância central na saúde holística. Sujeitos acostumados ao autoritarismo e à exclusão não podem elaborar sua autonomia. Tais cenários são mais propícios ao reprodutivismo, à passividade e à inação. De outra maneira, se construírmos espaços coletivos com liberdade, igualdade, pluralismo e dialogicidade, podemos construir, nesse bojo, uma cultura propícia à autonomia. Valorizando as contribuições de todos, e de suas pertenças culturais, podemos favorecer a construção desse espaço-processo.

(3) Para que a educação intercultural em saúde seja exequível, uma ressignificação da docência é crucial. Faz-se necessário romper com a práxis repetitiva, refletindo, criando, experimentando, avaliando e experimentando novamente alternativas pedagógicas nas variadas circunstâncias educativas. Temos presente, pois, que a alternativa que pleiteamos se apresenta como um novo modelo formativo, assentado numa nova cultura profissional do trabalho docente (QUEIROZ; NEVES, 2016), que ainda está distante de se estabelecer na prática. Precisamos, não como exceção, mas como regra, formar e educar nossos professores como intelectuais críticos, capazes de vivenciar em ações os discursos da liberdade, da igualdade, do pluralismo e da interculturalidade. Uma docência como tal poderia contribuir à produção de estados de bem-estar físicos, mentais e sociais na educação básica que possam produzir efeitos para além dos muros da escola.

(4) Autonomia e heteronomia são ideias necessariamente excludentes? O pensamento pós-estruturalista diria que não. Entre estes conceitos há muitos pontos de hibridismo, embora estes pareçam "cegos" à ciência clássica. A proposta é polêmica. Significa questionar o cânone do "terceiro excluído" (NICOLESCU, 1999). Representa admitir que um organismo poderia produzir e receber normas ao mesmo tempo. Este não foi nosso foco até o momento, mas estamos dispostos a abordá-lo na continuação dos trabalhos, para favorecer nossas interpretações e intervenções.

Em suma, defendemos uma educação em saúde multidimensional e processual, que tenha na interculturalidade e na reflexividade crítica docente seus fundamentos. Escolhemos uma concepção que pode e deve se efetivar na escola básica democrática.

Nessa direção, o estudo possibilitou identificar uma significativa influência da educação intercultural na construção de conceitos e condutas voltadas à saúde física, mental e social no âmbito onde a investigação ocorreu. Contudo, também foi notável que estes efeitos não podem nem devem ser limitados a escalas pontuais ou a momentos episódicos na esfera escolar, sendo imprescindível que a reflexividade crítica seja cultivada diariamente como um dos mais importantes referenciais da formação e da carreira docente na educação básica. Trata-se de um programa democrático que convém ser partilhado por todos os educadores, atuais e futuros. É também um objeto que carece ser muito mais pautado pela investigação acadêmica no país, em especial quanto ao ensino de Ciências.

\section{Considerações Finais}

Como sujeitos licenciandos e docentes podem construir ideias e atitudes críticoreflexivas que sejam favoráveis à promoção de uma educação em saúde de caráter intercultural na escola básica? 
Com a investigação em andamento, afirmamos que o desenvolvimento de dinâmicas dialógicas e práticas educativas interculturais conjuntamente com licenciandos e docentes pode alavancar a produção de identidades profissionais autômomas, comprometidas com a reflexividade crítica, a interculturalidade e a saúde holística em seu exercício docente na escola básica.

Explorando nexos entre a saúde, a cultura e a educação escolar, a análise pontuou a importância capital da interculturalidade e da reflexividade critica na capacitação docente para uma educação democrática em saúde. Pensar a formação de professores a partir desses princípios se revela como um programa de valorização do aprimoramento pessoal e profissional dos professores e das instituições escolares, possibilitando experimentações e reflexões por um ensino e uma sociedade melhor.

A pesquisa alavancou dinâmicas partipativas de formação com docentes da escola básica, construindo inteligibilidade, comunicação e deliberação em torno de um ensino que favoreça o bem-estar holístico. Contudo, os debates e práticas de ensino operacionalizados permitiram desestabilizar imaginários sociais naturalizados e desenvolver algumas intervenções práticas na direção que se propunha, porém eles também tornaram patente que existem muitos obstáculos ainda a contornar. A educação intercultural em saúde é uma lacuna a preencher, por meio de iniciativas individuais e coletivas.

Salientamos que a educação escolar pode e deve ser um campo de construção de uma abordagem positiva da diversidade, criando um cenário relativamente mais saudável. E o trabalho docente cabe ser um lugar fértil para o proativo, o criativo e o emancipatório, ainda que as mudanças sejam complicadas, lentas e paulatinas, principalmente em tempos políticos adversos como estes. Mesmo assim, esta é uma pauta que deveria reunir escola, academia e sociedade.

\section{Referências}

ALMEIDA FILHO, N. O que é saúde? Rio de Janeiro: EdFiocruz, 2000.

ALVES, F. (org.). Saúde, medicina e sociedade: uma visão sociológica. Lisboa: Pactor, 2013.

ARAÚJO, M. AMORIM, A. Percepções de professores sobre o uso de atividades lúdicas para tratar o tema "água e saúde" em ações de educação ambiental numa região semiárida. HOLOS, Natal, v. 6, p. 294-306, 2014.

ASSIS, S. S.; ARAÚJO-JORGE, T. C. O que dizem as propostas curriculares do Brasil sobreo tema saúde e as doenças negligenciadas?: aportes para a educação em saúde no ensino de ciências. Ciência \& Educação, Bauru, v. 24, n. 1, p. 125-140, 2018.

ASSIS, S. S.; PIMENTA, D. N.; SCHALL, V.T. A dengue nos livros didáticos de ciências e biologia indicados pelo programa nacional do livro didático. Ciencia \& Educação, Bauru, v.19, n. 3, p.633-656, 2013.

BHABHA, H. O local da cultura. Belo Horizonte: Ed. UFMG, 2013.

BRASIL. Ministério da Educação. Parâmetros curriculares nacionais: ciências naturais e suas tecnologias. Brasília: MEC, 1999.

BRASIL. Ministério da Educação e do Desporto. Resolução n. 2, de 7 abril de 1998. Institui as diretrizes curriculares nacionais para o ensino fundamental. Diário Oficial da União, Brasília, abr. 1998. 
BRICEÑO-LEÓN, R. Siete tesis sobre la educación sanitaria para la participación comunitaria. Cadernos de Saúde Pública, Rio de Janeiro, v. 12, n. 1, p. 7-30, 1996.

CANDAU, V. M.; SACAVINO, S. B.; MARANDINO, M.; BARBOSA, M. F. M.; MACIEL, A. G. Oficinas pedagógicas de direitos humanos. Petrópolis: Vozes, 1995.

CANGUILHEM, G. O normal e o patológico. São Paulo: Forense Universitária, 1990.

COELHO, M. H. A. D.; ALMEIDA FILHO, N. Normal-patológico, saúde-doença: revisitando Canguilhem. Physis: Revista de Saúde Coletiva, Rio de Janeiro, v. 9, n. 1, p. 13-36, jun. 1999.

DEJOURS, C. Por um novo conceito de saúde. Revista Brasileira de Saúde Ocupacional, São Paulo, v. 14, n. 54, p. 7-11, abr./jun. 1986.

ELLIOTT, J. Action research for education change. Buckingham: Open University Press, 1991.

ENTRE os muros da escola. Direção: Laurent Cantet. Produção: Caroline Benjo e Carole Scotta. Paris: Imovision, 2008. 1 DVD.

FERGUSON, M. A conspiração aquariana. Rio de Janeiro: Record, 1980.

FORQUIN, J. C. Escola e cultura. Porto Alegre: Artmed, 1994.

FRANÇA, V. H. MARGONARI, C. SCHALL, V. T. Percepção de professores do ensino básico em relação as suas práticas educativas sobre leishmanioses: um estudo em área endêmica em Minas Gerais. Ensaio: pesquisa em educação em ciências, Belo Horizonte, v. 15, n. 3, p. 35-51, 2013.

LÉVI-STRAUSS, C. Tristes trópicos. Rio de Janeiro: Rocco, 1996.

LUZ, M. T. Saúde. In: DICIONÁRIO da educação profissional em saúde. Rio de Janeiro: Fundação Oswaldo Cruz, Escola Politécnica de Saúde Joaquim Venâncio, 2009.

MCLAREN, P. Multiculturalismo crítico. São Paulo: Cortez, 1997.

MOREIRA, A. F. CANDAU, V. M. Currículo, conhecimento e cultura. In: BRASIL. Ministério da Educação. Indagações sobre currículo. Brasília: Secretaria de Educação Básica, 2008.

NÓVOA, A. Os professores e sua formação. Lisboa: Dom Quixote, 1992.

NICOLESCU, B. O manifesto da transdiciplinaridade. São Paulo: PRIOM, 1999.

ORGANIZAÇÃO MUNDIAL DA SAÚDE. Carta de Ottawa para a promoção da saúde. In: CONFERÊNCIA INTERNACIONAL SOBRE A PROMOÇÃO DA SAÚDE, 1., 1986, Ottawa. Disponível em: https://www. dgs.pt/documentos-e-publicacoes/carta-de-otawa-pdf1.aspx. Acesso em: 08 abr. 2020.

PIMENTA, S. G. Pesquisa-ação crítico colaborativa: construindo seu significado a partir de experiências com a formação docente. Educação e Pesquisa, São Paulo, v. 31, n. 3, p. 521-539, dez. 2005.

PIMENTA, S.G. GHEDIN, E. (org.). Professor reflexivo no Brasil: gênese e crítica de um conceito. São Paulo: Cortez, 2005.

PINK FLOYD. Another brick in the wall. 1979. Disponível em: https://www.youtube.com/ watch?v=YR5ApYxkU-U. Acesso em: 28 abr. 2020. 
QUEIROZ, P. P. A pesquisa e o ensino de história: espaços/processos de construção de identidade profissional. In: NIKITIUK, S. (org.). Repensando o ensino de história. São Paulo: Cortez, 2012. p. 103121.

QUEIROZ, P. P. NEVES, F. H. A formação do professor de sociologia e a educação intercultural. In: CONGRESSO IBERO-AMERICANO DE INVESTIGAÇÃO QUALITATIVA, 5., 2016, Porto. Atas [...]. [S.I.]: CIAIQ, 2016. v. 1, p. 250-259. Disponível em: https://proceedings.ciaiq.org/index.php/CIAIQ2019. Acesso em 8 abr. 2020.

SAFATLE, V. O que é uma normatividade vital?: saúde e doença a partir de Georges Canguilhem. Scientia Studia, São Paulo, v. 9, n. 1, p. 11-27, 2011.

SAMPAIO, A. F.; ZANCUL, M. S.; ROTTA, J. C. G. A educação em saúde na formação de professores em ciências naturais. Revista Electrónica de Investigación en Educación en Ciencias, Buenos Aires, v. 10, n. 2, p. 46-58, 2015.

SANTOS, B. S. Para uma pedagogia do conflito. In: SILVA, L. H.; AZEVEDO, J. C.; SANTOS, E. S. (org.). Novos mapas culturais, novas perspectivas educacionais. Porto Alegre: Sulina, 1996. p. 15-33.

SANTOS, B. S. Renovar a teoria crítica e reinventar a emancipação social. São Paulo: Boitempo, 2014.

SCHÖN, D. The reflective practioner. London: Temple Smith, 1983.

SOARES, M. N.; CHAPANI, D. T. Aproximações e desafios à experiência formativa por parte de licenciandos de ciências biológicas: considerações a partir de um subprojeto ligado ao programa novos talentos. Revista Brasileira de Pós-Graduação, Brasília, v. 12, n. 28, p. 361-383, set. 2015.

SCLIAR, M. História do conceito de saúde. Physis: Revista de saúde coletiva, Rio de Janeiro, v. 17, n. 1, p. 29-41, 2007.

TARDIF, M. Saberes docentes e formação profissional. Petrópolis: Vozes, 2005.

THIOLLENT, M. Metodologia da pesquisa-ação. São Paulo: Cortez, 1986.

TODOROV, T. O medo dos bárbaros: para além do choque entre civilizações. Petrópolis: Vozes, 2012. 